\title{
Palatability of beef steaks marinated with solutions of calcium chloride, phosphate, and (or) beef-flavoring
}

\author{
J.A. Scanga *, R.J. Delmore Jr. ${ }^{1}$, R.P. Ames ${ }^{2}$, K.E. Belk, J.D. Tatum, G.C. Smith \\ Department of Animal Sciences, Colorado State University, Fort Collins, CO 80523-1171, USA
}

\begin{abstract}
This study evaluated the efficacy of marination for increasing consumer acceptability of beef. Top-sirloin steaks from 28 USDA select steers were randomly assigned to one of six marination treatments: control (CT), $150 \mathrm{mM}$ calcium chloride (CA), 10\% solution of beef-flavoring/seasoning mixture (FL), CA and FL (CF), 2.5\% sodium phosphate and FL (PF), and tap water (TW). Steaks were marinated in vacuum pouches, aged for 7 days, cooked to $70^{\circ} \mathrm{C}$ and evaluated by a trained sensory panel. Marination with CA did not affect tenderness ratings, but increased $(P<0.05)$ bitter and metallic flavors compared to CT or TW treatments. Use of FL, alone or in conjunction with CA or sodium phosphate, increased $(P<0.05)$ tenderness and juiciness ratings and reduced $(P<0.05)$ bitterness and metallic flavors compared to CT, CA and TW marinades. Marination of beef, in vacuum pouches, is an effective method for increasing consumer acceptability and value beef.
\end{abstract}

Keywords: Beef; Tenderness; Calcium chloride; Phosphate; Marination

\section{Introduction}

To overcome beef toughness problems, researchers have investigated corrective actions that could be used to improve tenderness, reduce variability and increase consumer satisfaction of whole-muscle beef retail cuts. The benefits of chemical meat-enhancing agents (phosphate, $\mathrm{CaCl}_{2}$ and papain) have been well documented (Wang, Wier, Birkner \& Ginger, 1957; Kerth, Miller \& Ramsey, 1995; Morris, Theis, Miller, Acuff \& Savell, 1997) and the success of enhanced retail products, especially pork, is apparent in the US commercial meat industry. In addition to enhancing the flavor, tenderness and consumer acceptance of retail meat products, the ability to produce and sell value-added and water-added retail beef provides the beef industry access to a large and growing marketing opportunity.

\footnotetext{
* Corresponding author. Tel.: + 1-970-491-5226; fax: + 1-970-4910278 .

E-mail address: jscanga@lamar.colostate.edu (J.A. Scanga).

${ }^{1}$ Present address: Clougherty Packing Company, PO Box 58879, Los Angeles, CA 90058-0870, USA.

2 Present address: Certified Hereford Beef, PO Box 014059, Kansas City, MO 64101-4059, USA.
}

Sodium phosphate is commonly used in meat processing and has been documented to increase protein solubility and the water-binding ability of meat (Hellendoorn, 1962; Deatherage, 1963; Trout \& Schmidt, 1986). Smith, Simmons, McKeith, Betchel and Brady (1984) concluded that injection of brine containing sodium tripolyphosphate into pork longissimus increased juiciness and reduced WarnerBratzler shear values, and also increased juiciness when injected into beef semimembranosus. Addition of sodium phosphate (as either pyrophosphate or hexametaphosphate) also has been reported to prevent rigor mortis and increase tenderness of freshly slaughtered beef (Streitel, Ockerman \& Cahill, 1977).

Calcium chloride has been identified as a means for increasing beef tenderness (Kerth et al., 1995; Wheeler, Koohmaraie \& Crouse, 1991; Whipple \& Koohmaraie, 1992). However, a $10 \%$ injection of $0.3 \mathrm{M}$ calcium chloride has been shown to have an adverse effect on palatability, imparting a bitter, metallic and sour taste to the cooked product (Eilers et al., 1994; Morris et al., 1997). To compensate for the undesirable flavor characteristics associated with the use of calcium chloride, flavoring agents - used in conjunction with calcium chloride injection - have been shown to mask the offflavors (Morris et al.). 
Benefits of marinating (Whipple \& Koohmaraie, 1992) or injecting (Kerth et al., 1995; Koohmaraie, Whipple \& Crouse, 1990; Morgan, Miller, Mendez, Hale \& Savell, 1991) beef cuts, from 30 min to 5 days postmortem, with calcium chloride to increase tenderness by enhancing calcium-activated proteolysis are well documented. However, implementation of this technology has not progressed rapidly, probably due to the compromised flavor associated with its use (Eilers et al., 1994; Morris et al., 1997) and because of the recent USDA-FSIS proposed rule that would classify an injected, mechanically tenderized, chopped, ground or minced product that is contaminated with Escherichia coli O157:H7 as "adulterated" (USDA-FSIS, 1999). In the present study, a solution of beef-flavoring/seasoning mixture was added to solutions containing either phosphate or calcium chloride to determine: (1) if marination of beef retail cuts can be used as an effective mechanism to apply chemical enhancing agents, (2) if phosphate solutions can be used to increase the tenderness, juiciness and overall palatability of cooked beef steaks; and (3) if off-flavors associated with the use of a calcium chloride solution (as a marinade) can be masked using a flavoring/seasoning agent.

\section{Materials and methods}

\subsection{Product selection}

Top sirloin butts were obtained $24 \mathrm{~h}$ postmortem from the right side of USDA select fed steer carcasses $(n=28)$ in a commercial beef packing facility. Vacuumpackaged top sirloin butts were transported to the Colorado State University meat laboratory and fabricated into six steaks ( $2.54 \mathrm{~cm}$ thick) from the gluteus medius (excluding end cuts). Steaks were then trimmed to yield portions weighing $170 \pm 3 \mathrm{~g}$.

\subsection{Treatments}

Steaks from each top sirloin butt were assigned randomly to either a control (no marinade) or one of five marination-treatment groups: (1) calcium chloride, (2) flavoring/seasoning mixture, (3) calcium chloride and beef-flavoring/seasoning mixture, (4) sodium phosphate and beef-flavoring/seasoning mixture, and, (5) tap water. All solution volumes were added to the steaks to equal $25 \%$ of raw cut weight $(25 \% \mathrm{wt} / \mathrm{wt})$. Calcium chloride marination (CA) was applied via a $\mathrm{pH} 7.26$ solution of $150 \mathrm{mM}$ food grade calcium chloride (Spectrum, Gardena, CA). The flavoring/seasoning marinade (FL) treatment was applied via a $10 \%$ solution of a $\mathrm{pH}$ 5.29 flavoring/seasoning agent (Williams Seasoning, Inc., Product No. B01144, Lenexa, KS) that contained $48 \%$ salt, $24 \%$ hydrolyzed soy protein, $15 \%$ mal- todextrin, $7 \%$ dried beef stock and $6 \%$ spices and flavoring. The combined calcium chloride and beef flavor/ seasoning marinade $(\mathrm{CF})$ contained equal volumes of $150 \mathrm{mM}$ calcium chloride and $10 \%$ beef-flavoring/seasoning mixture solutions, $\mathrm{pH} 5.07$; the sodium phosphate and beef flavor/seasoning marinade (PF) contained equal parts of $2.5 \%$ sodium phosphate (BRIFISOL $^{\circledR 8} 85$ Instant, BK-Ladenburg Corp., Lodi, CA) and $10 \%$ beef-flavoring/seasoning mixture solutions, $\mathrm{pH}$ 6.79. All solutions were applied to the steaks in vacuum pouches to determine if the effect of chemical additives could be observed without using an invasive, surface penetrating process (i.e. needle injection).

\subsection{Packaging and cooking loss}

Steaks were individually weighed and vacuum packaged with nothing (control) or with the appropriate marination treatment solution in $20.3 \times 25.4 \mathrm{~cm}$ vacuum bags $(0.019 \mathrm{~mm}$ nylon and $0.057 \mathrm{~mm}$ polyethylene bag) with an oxygen transmission rate of $3.5 \mathrm{~cm}^{3} \times(0.065$ $\left.\mathrm{m}^{2}\right)^{-1} \times(24 \mathrm{~h})^{-1}$ at $21^{\circ} \mathrm{C}$ (Koch Supplies Inc., Kansas City, MO), aged for 7 days at $2^{\circ} \mathrm{C}$, frozen and stored at $-28.6^{\circ} \mathrm{C}$. Steaks were then thawed for $24 \mathrm{~h}$ at $2^{\circ} \mathrm{C}$, weighed and cooked on an electric char-broiler (Model 0B51, Hobart Corporation, Troy, OH). Each steak was turned during cooking every $4 \mathrm{~min}$ and the temperature was monitored during cooking using a digital probe thermometer (Atkins Technical Inc., Gainesville, FL) until a final internal temperature of $70^{\circ} \mathrm{C}$ was reached. Cooked steaks were then reweighed to determine weight loss during cooking.

\subsection{Sensory evaluation}

Warm samples were evaluated by a trained (Cross, Moen \& Stanfield, 1978) eight-member sensory panel for juiciness, muscle fiber tenderness, connective tissue amount and overall tenderness using 8-point rating scales $(8=$ extremely juicy, extremely tender, none or extremely tender; $1=$ extremely dry, tough, abundant or tough, respectively). Additionally, flavors (metallic, salty, bitter, beefy and soapy) were evaluated on a 3point scale $(0=$ none detectable, $1=$ slightly detectable and $2=$ very strong) by the same trained sensory panel, following AMSA (1995) guidelines. Panelists were trained to detect flavors using the procedures of Meilgaard, Civille and Carr (1991).

\subsection{Statistical analysis}

Individual panelist ratings for each sensory trait evaluated were averaged to determine mean sensory ratings for each trait for each steak. Random effects analysis of variance was conducted using the general linear models procedures of SAS (1988) for a split-plot design, with 
the random effect of top sirloin butt. Data were analyzed using a model that included the mean sensory rating as the dependent variate; the independent whole plot of top sirloin butt and the fixed, independent effects for marination treatment $(\mathrm{CT}, \mathrm{CA}, \mathrm{FL}, \mathrm{CF}, \mathrm{PF}$ and TW) within subprimal as the split plot. When appropriate, means were separated using Tukey's studentized range test.

\section{Results and discussion}

\subsection{Sensory characteristics}

Benefits of marinating (Whipple \& Koohmaraie, 1992) or injecting (Kerth et al., 1995; Koohmaraie et al., 1990; Morgan et al., 1991) beef cuts with calcium chloride to increase tenderness through enhanced calcium-activated proteolysis have been well documented, yet due to compromised flavor (Eilers et al., 1994; St. Angelo et al., 1991), practical implementation of this technology has not progressed rapidly. Morris et al. (1997) injected beef-flavoring into hot boned beef top rounds in attempts to mask the warmed-over, sour and bitter flavors associated with the use of calcium chloride. In the present study, a solution of beef-flavoring/ seasoning mixture was added to solutions containing either phosphate or calcium chloride to determine: (a) if phosphate solutions can be used to increase the tenderness, juiciness and overall palatability of cooked beef steaks and (b) if off-flavors associated with the use of a calcium chloride solution (as a marinade) can be masked using a flavoring/seasoning agent.

Steaks marinated with beef-flavoring, either solely or in combination with $\mathrm{CaCl}_{2}$ or phosphate, were rated (Table 1) as being juicier $(P<0.05)$, more tender $(P<0.05)$, overall tenderness and muscle fiber tenderness, and having less $(P<0.05)$ detectable connective tissue than steaks from the two control groups (no marinade or tap water) and steaks from the treatment that included only $\mathrm{CaCl}_{2}$. This is contradictory to results reported by Whipple and Koohmaraie (1992), who found that tenderness was increased when steaks were marinated in $\mathrm{CaCl}_{2}$ for 2 or 5 days. However, it was also noted that the $\mathrm{CaCl}_{2}$ marinade was not absorbed into the steaks (Table 3), explaining why $\mathrm{CaCl}_{2}$

Table 1

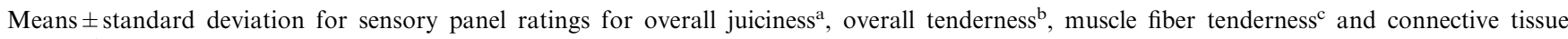
$\operatorname{amount}^{\mathrm{d}}(N=168)$

\begin{tabular}{lllll}
\hline Treatment & Juiciness & Overall tenderness & Muscle fiber tenderness & Connective tissue amount \\
\hline No marinade (control) & $4.64 \pm 0.51 \mathrm{z}^{\mathrm{f}}$ & $4.34 \pm 0.84 \mathrm{z}$ & $4.74 \pm 0.73 \mathrm{z}$ & $4.32 \pm 0.85 \mathrm{z}$ \\
$25 \% \mathrm{e}^{\mathrm{e}} 150 \mathrm{mM} \mathrm{CaCl}$ & & $4.98 \pm 0.78 \mathrm{z}$ & $4.65 \pm 0.88 \mathrm{z}$ \\
$25 \% 10 \%$ beef-flavoring & $4.95 \pm 0.73 \mathrm{z}$ & $4.68 \pm 0.86 \mathrm{z}$ & $5.53 \pm 0.69 \mathrm{y}$ & $5.12 \pm 0.79 \mathrm{y}$ \\
$25 \% \mathrm{CaCl}_{2}$ and beef-flavoring & $5.56 \pm 0.64 \mathrm{y}$ & $5.24 \pm 0.75 \mathrm{y}$ & $5.53 \pm 0.55 \mathrm{y}$ & $5.17 \pm 0.72 \mathrm{y}$ \\
$25 \%$ phosphate and beef-flavoring & $5.52 \pm 0.50 \mathrm{y}$ & $5.23 \pm 0.68 \mathrm{y}$ & $5.74 \pm 0.68 \mathrm{y}$ & $5.37 \pm 0.76 \mathrm{y}$ \\
$25 \%$ tap water control & $5.44 \pm 0.61 \mathrm{y}$ & $5.41 \pm 0.83 \mathrm{y}$ & $4.68 \pm 0.77 \mathrm{z}$ & $4.41 \pm 0.89 \mathrm{z}$ \\
\hline
\end{tabular}

a Overall juiciness was scored on an 8 -point scale, $1=$ extremely dry, $8=$ extremely juicy.

b Overall tenderness was scored on an 8 -point scale, $1=$ extremely tough, $8=$ extremely tender.

c Muscle fiber tenderness was scored on an 8 -point scale, $1=$ extremely tough, $8=$ extremely tender.

d Connective tissue amount was scored on an 8 -point scale, $1=$ abundant, $8=$ none.

e All solutions were added to the steaks to equal $25 \%$ of the weight of the raw product $(25 \% \mathrm{wt} / \mathrm{wt})$.

${ }^{\mathrm{f}}$ Means in the same column, lacking a common letter, differ $(P<0.05)$.

Table 2

Means \pm standard deviation for sensory panel ratings for bitterness ${ }^{\mathrm{a}}$, metallic taste ${ }^{\mathrm{b}}$, saltiness $^{\mathrm{c}}$, beefy flavor $^{\mathrm{d}}$ and soapiness $^{\mathrm{e}}(N=168)$

\begin{tabular}{llllll}
\hline Treatment & Bitter & Metallic & Salty & Beefy & Soapy \\
\hline No marinade (control) & $0.57 \pm 0.21 \mathrm{y}^{\mathrm{g}}$ & $0.27 \pm 0.14 \mathrm{y}$ & $0.05 \pm 0.09 \mathrm{z}$ & $0.41 \pm 0.16 \mathrm{z}$ & $0.08 \pm 0.13 \mathrm{w}$ \\
$25 \%{ }^{\mathrm{f}} 150 \mathrm{mM} \mathrm{CaCl}$ & & $0.49 \pm 0.21 \mathrm{x}$ & $0.05 \pm 0.08 \mathrm{z}$ & $0.40 \pm 0.22 \mathrm{z}$ & $0.06 \pm 0.09 \mathrm{wx}$ \\
$25 \% 10 \%$ beef-flavoring & $0.74 \pm 0.28 \mathrm{x}$ & $0.12 \pm 0.12 \mathrm{z}$ & $1.15 \pm 0.22 \mathrm{y}$ & $0.84 \pm 0.24 \mathrm{y}$ & $0.02 \pm 0.05 \mathrm{xy}$ \\
$25 \% \mathrm{CaCl}_{2}$ and beef-flavoring & $0.23 \pm 0.15 \mathrm{z}$ & $0.10 \pm 0.11 \mathrm{z}$ & $1.27 \pm 0.26 \mathrm{xy}$ & $0.77 \pm 0.23 \mathrm{y}$ & $0.00 \pm 0.02 \mathrm{yz}$ \\
$25 \%$ Phosphate and beef-flavoring & $0.33 \pm 0.20 \mathrm{z}$ & $0.06 \pm 0.08 \mathrm{z}$ & $1.35 \pm 0.30 \mathrm{x}$ & $0.82 \pm 0.18 \mathrm{y}$ & $0.00 \pm 0.00 \mathrm{z}$ \\
$25 \%$ tap water & $0.52 \pm 0.22 \mathrm{y}$ & $0.28 \pm 0.18 \mathrm{y}$ & $0.00 \pm 0.02 \mathrm{z}$ & $0.41 \pm 0.18 \mathrm{z}$ & $0.06 \pm 0.08 \mathrm{wxy}$
\end{tabular}

a Bitterness was scored on an 3-point scale, $0=$ not bitter, $2=$ extremely bitter.

b Metallic taste was scored on an 3-point scale, $0=$ not metallic, $2=$ extremely metallic.

c Saltiness was scored on an 3-point scale, $0=$ not salty, $2=$ extremely salty.

d Beefy flavor was scored on an 3-point scale, $0=$ extremely weak, $2=$ extremely beefy.

e Soapiness was scored on an 3-point scale, $0=$ not soapy, $2=$ extremely soapy.

${ }^{\mathrm{f}}$ All solutions were added to the steaks to equal $25 \%$ of the weight of the raw product $(25 \% \mathrm{wt} / \mathrm{wt})$.

g Means in the same column, lacking a common letter, differ $(P<0.05)$. 
Table 3

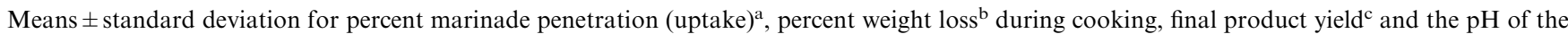
marination solution $(N=168)$

\begin{tabular}{|c|c|c|c|c|}
\hline Treatment & Marinade uptake (\%) & Weight loss during cooking $(\%)$ & Final yield $(\%)$ & Marination solution, $\mathrm{pH}$ \\
\hline No marinade (control) & $-4.7 \pm 1.7 \mathrm{z}^{\mathrm{e}}$ & $24.9 \pm 4.0 \mathrm{yz}$ & $71.6 \pm 4.0 \mathrm{z}$ & - \\
\hline $25 \%{ }^{\mathrm{d}} 150 \mathrm{mM} \mathrm{CaCl}_{2}$ & $-1.7 \pm 2 y$ & $27.0 \pm 3.9 y$ & $71.8 \pm 4.4 z$ & 7.26 \\
\hline $25 \% 10 \%$ beef-flavoring & $2.8 \pm 2.1 \mathrm{x}$ & $25.3 \pm 4.4 \mathrm{x}$ & $76.7 \pm 4.5 y$ & 5.29 \\
\hline $25 \% \mathrm{CaCl}_{2}$ and beef-flavoring & $3.8 \pm 1.6 w x$ & $25.8 \pm 4.2 y$ & $77.1 \pm 4.8 y$ & 5.07 \\
\hline $25 \%$ phosphate and beef-flavoring & $4.6 \pm 3.1 \mathrm{w}$ & $22.3 \pm 4.5 z$ & $81.2 \pm 4.1 \mathrm{x}$ & 6.79 \\
\hline $25 \%$ tap water & $-3.5 \pm 3.5 z$ & $27.4 \pm 4.7 y$ & $70.0 \pm 6.2 \mathrm{z}$ & - \\
\hline
\end{tabular}

a Percent marinade uptake was calculated using weights taken prior to marination and before cooking.

b Percent weight loss was calculated using weights taken immediately prior to and following cooking.

c Percent final yield was calculated using weights taken prior to marination and immediately following cooking.

d All solutions were added to the steaks to equal $25 \%$ the weight of the raw product $(25 \% \mathrm{wt} / \mathrm{wt})$.

e Means in the same column, lacking a common letter, differ $(P<0.05)$.

marination did not improve the tenderness of the cooked steaks. Among steaks in the marinades that included a beef-flavoring component, there were no differences $(P<0.05)$ in juiciness, overall tenderness, muscle fiber tenderness or connective tissue content (Table $1)$.

Trained panelist flavor ratings indicated that steaks marinated with $\mathrm{CaCl}_{2}$ had the most $(P<0.05)$ detectable bitter and metallic off-flavors compared to steaks in the two control groups and in all other marinade treatments, whereas steaks marinated in solutions that contained beef-flavoring, either solely or in combination with other additives, were less bitter $(P<0.05)$ and less metallic $(P<0.05)$ than non-marinated steaks and steaks marinated in tap water (Table 2). The addition of a beef-flavoring agent masked the bitter and metallic flavors that were detected in steaks marinated with 150 $\mathrm{mM} \mathrm{CaCl} 2$. Additionally, steaks marinated with solutions that contained a beef-flavoring agent were also described as having a beefier $(P<0.05)$ flavor than steaks from all other marinade treatments. Although the addition of beef-flavoring to the marinade reduced the bitter and metallic off-flavors, not surprisingly, it also dramatically increased $(P<0.05)$ the saltiness of the cooked, marinated steaks compared to steaks from the two control (no marinade or tap water) groups and steaks marinated with $\mathrm{CaCl}_{2}$. Mean panelist ratings of the cooked marinated steaks for the presence of a soapy off-flavor were below 1.0 for all marinade treatments, and the steaks marinated in solutions that contained a beef-flavoring agent were rated as being less soapy $(P<0.05)$ than steaks in the non-marinated control group (Table 2).

\subsection{Steak yields}

Steaks were weighed prior to marination, before cooking and following cooking to determine the uptake of marinade into the raw steak during marination and the weight lost during cooking. Steaks marinated in solutions of higher $\mathrm{pH}$, with strong buffering capacities, should have increased water binding ability, compared to those steaks that were marinated in solutions with a $\mathrm{pH}$ close to, or below, the isoelectric point of meat. In this study (Table 3), steaks marinated in a solution of high $\mathrm{pH}$ that contained phosphate and beef flavoring absorbed more $(P<0.05)$ marinade solution than control steaks or steaks marinated with $\mathrm{CaCl}_{2}$ alone or beef-flavoring alone (but not than steaks marinated with both $\mathrm{CaCl}_{2}$ and beef-flavoring). Steaks marinated with $\mathrm{CaCl}_{2}$, although having the highest $\mathrm{pH}$ (7.26), did not absorb the marinade solution (Table 3). It is thought that this occurred because of the weak buffering capacity and ionic strength of the $\mathrm{CaCl}_{2}$, whereas when the flavoring solution was added to the marinade, the salt concentration increased the ionic strength of the solution and increased the absorption of the marinade solution. Control steaks (no marinade or tap water) had the greatest $(P<0.05)$ weight loss during marination. Steaks in the no-marinade control group and those that were marinated in a solution that contained phosphate and beef flavoring had lower $(P<0.05)$ weight loss during cooking than steaks in all other treatments and tap water controls. Because of the loss of free water during marination, the control (no marinade or tap water) steak weight loss during cooking was similar $(P<0.05)$ to all other marination treatments, but control (no marinade or tap water) steak final yields were lower $(P<0.05)$ than steaks marinated in solutions of beefflavoring, either solely or in combination with $\mathrm{CaCl}_{2}$ or phosphate (Table 3).

\section{Conclusions}

This study indicated that the use of marination effectively enhanced the palatability characteristics of beef steaks, especially when marinade solutions contained a beef-flavoring additive. In addition to improving perceived tenderness, marinades that incorporated a 
beef-flavoring agent also reduced off-flavors and increased total cooked product yields. Marination of beef steaks, especially with a beef-flavoring agent, is an effective and practical means to improve cooked beef palatability.

\section{References}

AMSA (1995). Research guidelines for cookery, sensory evaluation, and instrumental tenderness measurements of meat. Chicago, IL: American Meat Science Association and National Live Stock and Meat Board.

Cross, H. R., Moen, R., \& Stanfield, M. S. (1978). Training and testing of judges for sensory analysis of meat quality. Food Technology, $32,48-52$.

Deatherage, F.E. (1963). The effects of water and inorganic salts on tenderness. In: Proceedings of Campbell's Soup Company, Meat Tenderness Symposium (pp. 45-68). Camden, NJ.

Eilers, J. D., Morgan, J. B., Martin, A. M., Miller, R. K., Hale, D. S., \& Acuff, G. R. et al. (1994). Evaluation of calcium chloride and lactic acid injection on chemical, microbiological and descriptive attributes of mature cow beef. Meat Science, 38, 443-451.

Hellendoorn, E. W. (1962). Water-binding capacity of meat as affected by phosphates. Food Technology, 16, 119-124.

Kerth, C. R., Miller, M. F., \& Ramsey, C. B. (1995). Improvement of beef tenderness and quality traits with calcium chloride injection of beef loins 48 hours postmortem. Journal of Animal Science, 73, 750-756.

Koohmaraie, M., Whipple, G., \& Crouse, J. D. (1990). Acceleration of postmortem tenderization in lamb and Brahman-cross beef carcasses through infusion of calcium chloride. Journal of Animal Science, 68, 1278-1283.

Meilgaard, M., Civille, G. V., \& Carr, B. T. (1991). Sensory evaluation techniques (2nd ed.). Boca Raton, FL: CRC Press (pp. 135-186).
Morgan, J. B., Miller, R. K., Mendez, F. M., Hale, D. S., \& Savell, J. W. (1991). Using calcium chloride injection to improve tenderness of beef from mature cows. Journal of Animal Science, 69, 4469-4476.

Morris, C. A., Theis, R. L., Miller, R. K., Acuff, G. R., \& Savell, J. W. (1997). Improving the flavor of calcium chloride and lactic acid injected mature beef top round steaks. Meat Science, 45, 531-537.

SAS (1988). SAS/STAT ${ }^{\mathrm{R}}$ user's guide (Release 6.03). Cary, NC: SAS Inst.

Smith, L. A., Simmons, S. L., McKeith, F. K., Betchel, P. J., \& Brady, P. L. (1984). Effects of sodium tripolyphosphate on physical and sensory properties of beef and pork roasts. Journal of Food Science, 49, 1636-1637.

St. Angelo, A.J., Koohmaraie, M., Crippen, K.L., \& Crouse, J. (1991). Acceleration of tenderization/inhibition of warmed-over flavour by calcium chloride-antioxidant infusion into lamb carcass. Journal of Food Science, 56, 359-362.

Streitel, R. H., Ockerman, H. W., \& Cahill, V. R. (1977). Maintenance of beef tenderness by inhibition of rigor mortis. Journal of Food Science, 42, 583-585.

Trout, G. R., \& Schmidt, G. R. (1986). Effect of phosphate on the functional properties of restructured beef rolls: the role of $\mathrm{pH}$, ionic strength, and phosphate type. Journal of Food Science, 51, 14161422.

USDA-FSIS (1999). FSIS issues policy statement on beef and E. coli O157:H7 (19 January, 1999). USDA-Food Safety and Inspection Service. Washington DC.

Wang, H., Wier, C.E., Birkner, M.L. and Ginger, B. (1957). The influence of enzyme tenderizers on the structure and tenderness of beef. Proceedings of the 9th Research Conference. American Meat Institute Foundation, p. 72.

Wheeler, T. L., Koohmaraie, M., \& Crouse, J. D. (1991). Effects of calcium chloride injection and hot boning on the tenderness of round muscles. Journal of Animal Science, 69, 4871-4875.

Whipple, G., \& Koohmaraie, M. (1992). Freezing and calcium chloride marination effects on beef tenderness and calpastatin activity. Journal of Animal Science, 70, 3081-3085. 